\title{
Possible index of fish quality for release determined by behavior of metamorphosing larvae.
}

\author{
YOSHITAKA SAKAKURA ${ }^{1}$ AND KATSUMI TSUKAMOTO ${ }^{2}$
}

\begin{abstract}
1 Faculty of Fisheries, Nagasaki University, Bunkyo-machi 1-14, Nagasaki, 852-8521, Japan (sakakura@net.nagasaki-u.ac.jp) and 2 Ocean Research Institute, The University of Tokyo, Nakano-ku, Tokyo, 164-8639, Japan
\end{abstract}

SUMMARY: The seedlings for stock enhancement are required to have adequate behavioral characteristics (fish quality), which enable them to adapt to the natural environment after release. Screening of index behaviors, which reflect fish quality, should be an important approach. In this point of view, we have been investigating aggressive behavior in the seedlings of yellowtail (Seriola quinqueradiata) and Japanese flounder (Paralichthys olivaceus), because aggressive behavior has an important role for the survival in the early life stages of these 2 species. We found typical shivering behaviors in the metamorphosing larvae and named them J-posture in yellowtail and $\Omega$ -posture in Japanese flounder, respectively. Both postures were significantly and positively related to aggression in the juvenile stage, and we can predict which larva will become an aggressive juvenile. We propose that these postures will be applicable for future index of fish quality for release.

\section{KEYWORDS: stock enhancement, fish quality, aggressive behavior, larvae, metamorphosis}

\section{INTRODUCTION}

Stock enhancement has been getting more and more popular in the world in recent years. In Japan, more than 200 millions of seedlings for both stock enhancement and aquaculture are produced in a year ${ }^{1)}$ and increased number of seedlings are released into the field. However, the catch of the target species does not necessarily increase. ${ }^{2)}$ Since the seedlings for stock enhancement are required to have adequate behavioral characteristics (fish quality ${ }^{3}$ ), which enable them to adapt to the natural environment after release, ${ }^{3-5)}$ one reason for these unsatisfying results of stock enhancement might be a lack of the attentions to the problems of fish quality.

Many fish species develop social behaviors in their early life stages and social behaviors have significant biological and ecological roles for survival. ${ }^{6-8)}$ Therefore, screening of index behaviors, which reflect fish quality, should be important and practical approach for effective stock enhancement. Recent progress of seedling production technique has enabled us to observe behaviors in the early life stages of fishes ${ }^{9-14)}$ and some experimental studies have demonstrated that behavioral index of fish quality is applicable for predicting stocking effectiveness. ${ }^{5,15,16)}$ From this point of view, we have been investigating ontogeny of aggressive behavior in the seedlings, because aggressive behavior has an important role for the survival in the early life stages of fishes. ${ }^{5,17,18)}$ Moreover, behavioral study in the early life stages of fishes can provide basic biological information for improving seedling production techniques, because aggressive behavior including cannibalistic behavior can cause economical loss in the process of seedling production. $^{19)}$

Here we review our recent behavioral studies on the yellowtail (Seriola quinqueradiata) and the Japanese flounder (Paralichthys olivaceus), which are major target species for stock enhancement in Japan, and present perspectives of fish quality research.

\section{ONTOGENY OF AGGRESSIVE BEHAVIOR}

From the behavioral observation from hatching the rearing pond and experimental tanks, the onset of aggressive behavior in yellowtail was just after the transition from larva to juvenile stage and it developed thereafter (Fig.1). ${ }^{20)}$ Increase in size variation following development ceased corresponding to the onset of aggressive behavior and cannibalism (Fig.2).

In wild conditions, juvenile yellowtail schools are formed by the same batch as estimated from age composition. ${ }^{21)}$ They aggregate to drifting seaweed in current rips, and forage on pelagic copepods and fish 


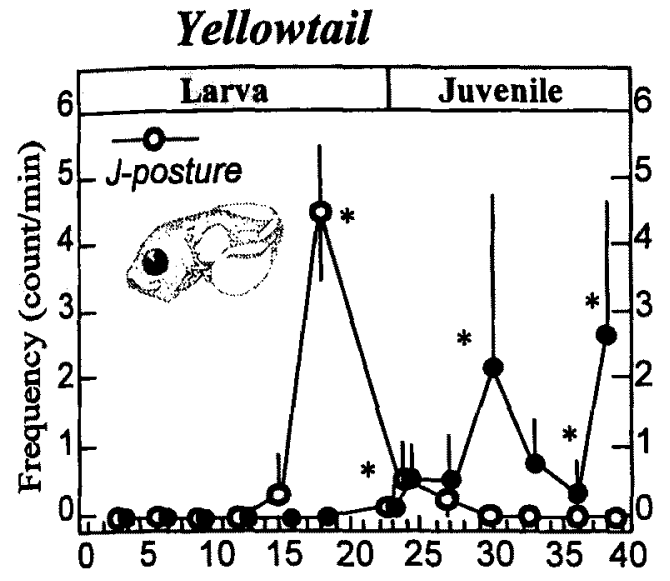

Japanese flounder

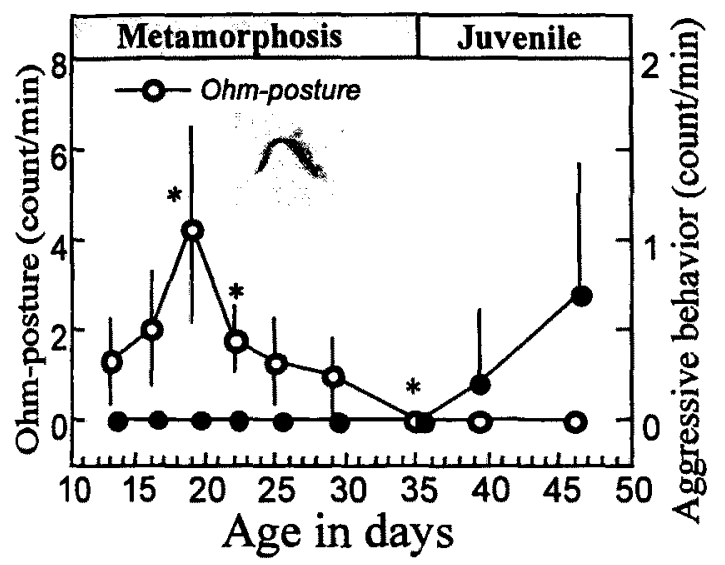

Fig. 1 Ontogenetic changes of aggressive behavior in yellowtail (upper) ${ }^{20)}$ and Japanese flounder (lower). ${ }^{23)}$ Closed circle and vertical bar represent mean frequency of aggressive behavior and standard deviation, respectively $(n=\varnothing)$. Open circle indicates mean frequency of J-posture for yellowtail and Ohm-posture for Japanese flounder. Asterisk shows significant difference against the former observation (U-test p<0.05).

larvae which are not associated with the seaweed. ${ }^{20)}$ Therefore, schools of juveniles in wild conditions are assumed to be in a similar condition as those of rearing ponds, and do not compete for the food resources of drifting seaweed. Field observations also revealed that the body sizes of school members are uniform (Coefficient of variation $=15 \%$ ), and that cannibalism occurs among school members. ${ }^{20)}$ Therefore, aggressive behavior of yellowtail is assumed to make the body size of school members uniform both in wild and rearing conditions. The uniformity in body size among fish schools is considered to minimize the individual predation risk by predator confusion. ${ }^{22)}$ Synthesizing these findings, the balance between schooling and aggression of yellowtail regulates the size of school members as uniform and it is interpreted as a tactic to increase predator avoidance in early life stages.

During the transition phase from larva to juvenile (metamorphosis) in yellowtail, typical shivering behavior with 'J-posture' was observed and it disappeared in juvenile stage. ${ }^{20)}$ As we describe in the next section, there was a positive correlation between J-posture in metamorphosing stage and aggressive behavior in juvenile stage of this species.

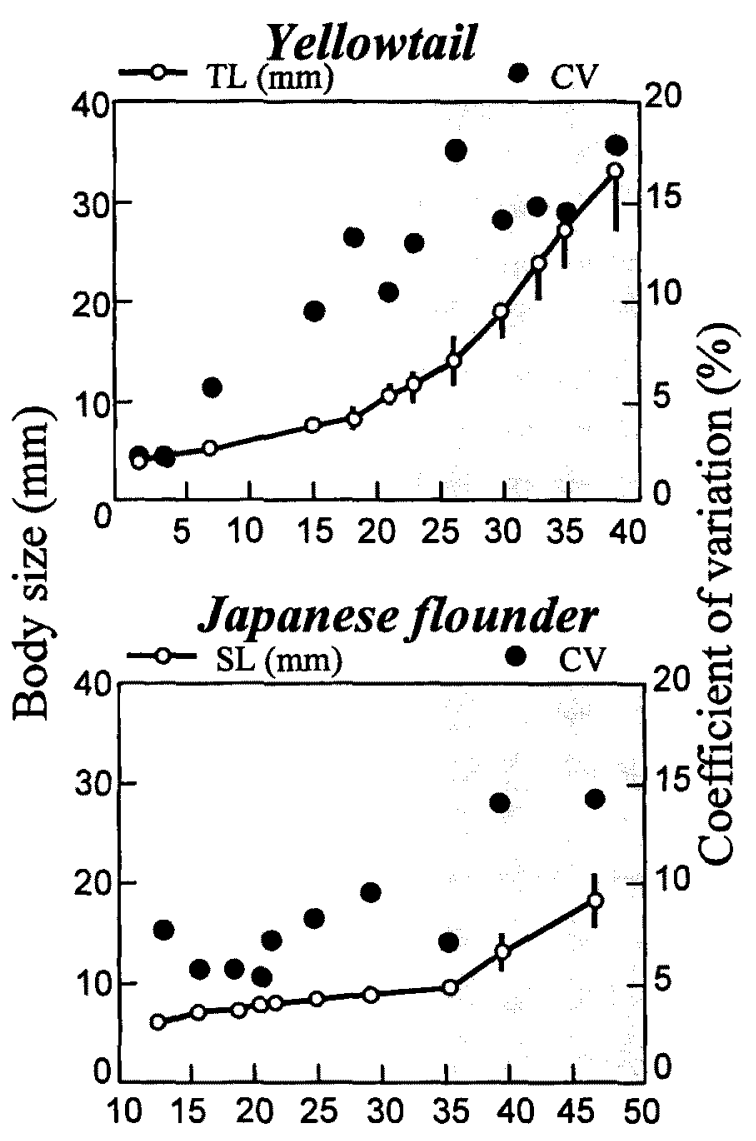

Age in days

Fig. 2 Growth curve and size variation in yellowtail (upper) ${ }^{20)}$ and Japanese flounder (lower). ${ }^{23)}$ Open circle and vertical bar represent average body size and standard deviation, respectively $(n=30-50)$. Closed circle indicates coefficient of variation (CV, \%) of body size, and shaded area represents the juvenile stage. Note the difference of $\mathrm{CV}$ between juvenile and just before juvenile stage in flounder is larger than that of yellowtail.

In the Japanese flounder (Paralichthys olivaceus), at the same behavioral changes in yellowtail, the onset of aggressive behavior was from the completion of metamorphosis (Fig.1) ${ }^{23)}$ Also, typical shivering behavior, which is quite similar to J-posture of yellowtail and had 
been named $\mathrm{Ohm}(\Omega)$-posture, ${ }^{24)}$ was frequently observed in the metamorphosing stage (Fig.1). We have confirmed that $\Omega$-posture is not directly related to the feeding behavior, although it looks like an S-spike posture that is a common attacking posture of food items in fish larvae. ${ }^{23)}$ The change of size variation from metamorphosis to juvenile stage of Japanese flounder was larger than that of yellowtail (Fig.2). Metamorphosing Japanese flounder larvae appear in high population density at inshore region, then complete metamorphosis, and settle (e.g. Noichi ${ }^{25}$ ). After settlement, when they become juvenile, onset of aggressive behavior may have a function for spacing and offshore migration thereafter.

\section{BEHAVIOR DURING METAMORPHOSIS CAN PREDICT JUVENILE AGGRESSION}

Based on the behavioral observation, we hypothesized that there may be correlation between metamorphosing behavior (J-posture, $\Omega$-posture) and aggressive behavior in juvenile stage. We examined the transition from the behavior in larva period (J-posture, $\Omega$-posture) to aggressive behaviour (juvenile period), tagging fish individually by otolith marking, which is almost certainly the only marking method applicable in behavioral experiments with fish larvae and juveniles as it is known not to affect behaviour, growth or survival. ${ }^{2627)}$ We sorted the metamorphosing larva into 2 categories, J-fish which showed J-posture strongly and non-J fish for yellowtail, and $\Omega$-fish and non- $\Omega$ fish for Japanese flounder, respectively. 200 fish in one category were marked with otolith by Alizarin complexone (ALC) and the same number of unlabeled fish of another category were kept in the same rearing tank until the developmental stage is completely defined as juvenile and aggressive behavior was often observed in the rearing tank. Behavioral observation was conducted in order to classify the social rank by the video image analysis and ALC check in the otolith was examined after the experiment to judge the larval behavior of each juvenile.

In yellowtail, dominant fish coincided significantly with the J-fish, indicating the possibility that fish formerly showing strong J-posture become aggressive fish as they grow (Table 1). ${ }^{18)}$ Dominant fish were significantly larger than subordinate fish whereas there was no significant difference in size between J-posture fish and non-J fish. Comparing the distribution to a Chi-square table in Japanese flounder in the same manner as yellowtail, dominant fish coincided significantly with the $\Omega$-fish. ${ }^{17}$ ) Therefore, same as the yellowtail, it was revealed that larva formerly showing strong $\Omega$-posture become aggressive fish as they grow. Considering the ontogenetic changes in the J- or $\Omega$-posture and aggressive behavior, these larval behaviors can be defined as precursor behaviors of aggressive behavior of these 2 species.

Since dominant juvenile flounder were significantly larger in size than subordinate fish and $\Omega$-fish becomes dominant in the juvenile stage, we hypothesized that $\Omega$-fish will show higher growth performance than non- $\Omega$ fish. From the back-calculation method using otolith daily increments, we examined the growth history of each individual. $\Omega$-fish showed significantly higher growth in the juvenile stage than non- $\Omega$ fish, whereas growth of $\Omega$-fish during the metamorphosing stage was as same as that of non- $\Omega$ fish. ${ }^{17)}$

Table 1 Chi-square table to determine the correlation between aggressive dominant (juvenile stage) and prior tendency of J-posture (larva stage) in yellowtail. ${ }^{18}$ ) Asterisks indicate significant difference (*; G-test $p<0.05$, **; Student's t-test $\mathrm{p}<0.01$, respectively).

\begin{tabular}{cccc}
\hline Category & J-posture & Non-J & SUM \\
\hline Dorninant & $6^{*}$ & 2 & $8(21.2 \pm 3.0 \mathrm{~mm} \mathrm{TL} *)$ \\
Subordinate & 7 & 14 & $21(16.3 \pm 1.8 \mathrm{~mm} \mathrm{TL})$ \\
SUM & 13 & 16 & 29 \\
\hline
\end{tabular}

Synthesizing these evidences, we can predict the aggression and growth performance from the behavior in the metamorphosing stage. And these larval behaviors can be good candidates for the fish quality for release. Since seedling production is costly and laborious, it will be very informative to estimate the fish quality as early as possible.

\section{COCLUSION}

Behavioral observation revealed that the onset of aggressive behavior both in yellowtail and Japanese flounder is after the transition from metamorphosis to juvenile stage. Specific behaviors in the metamorphosing stage, such as J-posture in the yellowtail and $\Omega$-posture in Japanese flounder, indicated not only the magnitude of aggression but also the high growth performance in the 
juvenile stage. We propose that these metamorphosing behaviors can be good and applicable index for fish quality for release, because these behaviors can be easily observed both in the rearing tank and the experimental tanks.

However, next questions arise; why metamorphosing larva show these specific postures and how these individual difference in behaviors occur in the very early developmental stage of fishes? So far, we have confirmed that both $J$-posture and $\Omega$-posture are not the feeding related behaviors, since these postures are equally observed regardless the presence or absence of food items. ${ }^{18,23)}$ Since metamorphosis in fishes undergoes drastic morphological, physiological and ecological changes, ${ }^{28)}$ we can easily expect the significant development in the central nervous system and changes in behaviors during this stage. Recent nutritional studies about the effects of dietary highly saturated fatty acid (DHA) on the yellowtail seedlings have demonstrated that, DHA enhances the development of central nervous system during metamorphosing and early juvenile stage, and the developments in nerve systems are essential for the onset of schooling behavior in the juvenile stage rather than the other morphological features. ${ }^{29,30)}$ Therefore, we assume the critical involvement of developments in the central nervous system on the index behaviors of fish quality for release. Further study is required to answer the above questions.

We have realized that in the process of the study on fish quality as follows we need to carry out the stocking experiment in the field using behavioral index which directly links to mortality in the field. ${ }^{3)}$ Using this index, we quantify the quality of seedlings The index behavior presented here are all conducted under the experimental conditions. Thus, we have to carry out the field study using these index behaviors and determine the stocking effectiveness. Then, we will be able to sort the fish with behavioral fitness for release. Also we believe these behavioral studies in the early life stages of fishes can provide not only the basic biological information but also the insight on the early life history of marine fishes, which are difficult to observe in the natural conditions.

\section{ACKNOWLEDGEMENTS}

This study was partly supported by the research grant for the Improvement of Japanese Flounder Quality for Stock
Enhancement to KT from Fisheries Agency of Japan. YS was funded by the COE program at the Ocean Research Institute, The University of Tokyo and the Grants-in-Aid for Scientific Research from Japan Society for the Promotion of Science.

\section{REFERENCE}

1. Honma A Aquaculture in Japan. Japan FAO Association, Tokyo, 1993; pp98.

2. Masuda $R$ and Tsukamoto $K$. Stock enhancement in Japan: review and perspective. Bull. Mar. Sci., 1998; 62: 337-358.

3. Tsukamoto K, Kuwada H, Uchida K, Masuda R, and Sakakura Y. Fish quality and stocking effectiveness: Behavioral approach. In: Howell BR, Moksness E, and Svåsand T (eds) Proceedings of First International Sympasium on Stock Enhancement and Sea Ranching. Blackwell, London, 1999; 205-218.

4. Olla BL, Davis MW, and Ryer CH. Behavioral deficits in hatchery-reared fish: potential effects on survival following release. Aquaculture and Fish Management 1994; 25 : 19-34.

5. Furuta S. Predation on juvenile Japanese flounder (Paralichthys olivaceus) by diurnal piscivorous fish: Field observations and laboratory experiments. In: Watanabe Y, Yamashita Y, and Oozeki Y (eds) Survival Strategies in Early Life Stages of Marine Resounces. Balkema, Rotterdam, 1996; 285-294.

6. Noakes DLG. Social behaviour as it influences fish production. In: Gerking SD (ed) Ecology of Freshwater Fish Prochuction. Blackwell, Oxford. 1978; 360-382.

7. Noakes DLG and Godin JGJ. Ontogeny of behavior and concurrent developmental changes in sensory systems in teleost fishes. In: Hoar WS and Randall DJ (eds) Fish physiology, Vol. XI part B. Academic Press, San Diego, 1988; 345-395.

8. Huntingford FA. Development of behaviour in fish. In: Pitcher TJ. (ed) Behaviour of Teleost Fishes, Second Edition. Chapman \& Hall, London, 1993; 57-83.

9. Seikai T. Metamorphosing and settlement processes of flatfish larvae analyzed from rearing experiments. Bull. Jap. Soc. Fish. Ocean 1985; 47\&48: 81-84.

10. Fukuhara $O$. Study on the development of functional morphology and behaviour of the larvae of eight commercially valuable teleost fishes. Contributions Fish Res. Japan Sea Block 1992; 25 : 1-122.

11. Fuiman LA and Magurran AE. Development of predator defenses in fishes. Rev. Fish. Biol. Fish. 1994; 4: 145-183.

12. Masuda $\mathrm{R}$ and Tsukamoto $\mathrm{K}$. The ontogeny of schooling behaviour in the striped jack. J. Fish. Biol. 1998; 52: 483-493.

13. Masuda $\mathrm{R}$ and Ziemann, DA. Ontogenetic changes of learning capability and stress recovery in the Pacific threadfin Polydactylus sexfilis juveniles. J. Fish Biol. 2000; 56: 1239-1247.

14. Miyazaki T, Shiozawa S, Kogane T, Masuda R, Maruyama $K$ and Tsukamoto $K$. Developmental changes of the light intensity threshold for school formation in the striped jack Pseudocaranx dentex. Mar. Ecol. Prog. Ser, 2000; 192: 267-275.

15. Tsukamoto K, Masuda S, Endo M, and Otake T. 1990. Behavioral characteristic of the ayu, Plecoglossus altivelis, as predictive indices for stocking effectiveness in rivers. Nippon Suisan Gakkaishi 56: 1177-1186.

16. Uchida $\mathrm{K}$, Kuwada $\mathrm{H}$, and Tsukamoto $\mathrm{K}$. Tilting behaviour, a fear response to frightening stimuli, as a possible predictive index for stocking effectiveness in the juveniles or red sea bream Pagrus major. Nippon Suisan Gakkaishi 1993; 59: 991-999. in Japanese with English abstract 
17. Sakakura Y. Studies on the ontogeny of aggressive behavior in fishes. Nippon Suisan Gakkaishi 2001; 67: 605-609. in Japanese

18. Sakakura $\mathrm{Y}$ and Tsukamoto $\mathrm{K}$ Ontogeny of aggressive behaviour in schools of yellowtail Seriola quinqueradiata. Env. Biol. Fish. 1999; 56: 231-242.

19. Smith C and Reay P. Cannibalism in teleost fishes. Rev. Fish Biol. Fisheries. 1991; 1: 41-64.

20. Sakakura $Y$ and Tsukamoto $K$. Onset and development of cannibalistic behaviour in early life stage of yellowtail. J. Fish Biol. 1996; 48: 16-29.

21. Sakakura $Y$ and Tsukamoto K. Age composition in the schools of juvenile yellowtail, Seriola quinqueradiata, associated with drifting seaweeds in the East China Sea Fish Sci. 1997; 63: $37-41$.

22. Pitcher TJ and Parrish. JK. Functions of shoaling behaviour in teleosts. In: Pitcher TJ (ed) Behoviour of Teleast Fishes, Chapman \& Hall, London, 1993; 363-439.

23. Sakakura $Y$ and Tsukamoto $K$. Onset and development of aggressive behavior in the early life stage of Japanese flounder. Fish Sci 2001 (submitted).

24. Fukuhara $O$. Morphological and functional development of Japanese flounder in early life stage. Bull. Jap. Soc. Sc. Fish. 1986; 52: 81-91.

25. Noichi T. Early life history. In: Minami T, Tanaka M (eds) Biology and Stock Enhancement of Japanese Flounder. Kouseisya Kouseikaku, Tokyo, 1997: 25-40. in Japanese

26. Tsukamoto K. Mass-marking of ayu eggs and larvae by tetracycline-tagging of otoliths. Bull. Japan. Soc. Sci. Fish. 1985; 51: 903-911.

27. Tsukamoto K, Y. Seki Y, Oba T, M. Oya M and Iwahashi. M. Application of otolith to migration study of salmonids. Physiol. Ecol. Japan. 1989; 1: 119-140.

28. Balon EK. Reflections on some decisive events in the early life of fishes. Trans. Amer. Fish. Soc. 1984; 113: 178-185.

29. Masuda R, Takeuchi T, Tsukamoto K, Sato S, Shimizu K and Imaizumi $\mathrm{K}$. Incorporation of dietary docosahexaenoic acid into the central nervous system in the yellowtail Seriola quinqueradiata. Brain Behav. Evol 1999; 53: 173-179.

30. Masuda R, Takeuchi T, Tsukamoto K, Ishizaki Y, Kanematsu $M$ and Imaizumi $K$ Critical involvement of dietary docosahexaenoic acid in the ontogeny of schooling behaviour in the yellowtail J. Fish Biol. 1998; 53: 471-484. 